\title{
Detection of calprotectin in inflammatory bowel disease: Fecal and serum levels and immunohistochemical localization
}

\author{
SHUHEI FUKUNAGA ${ }^{1}$, KOTARO KUWAKI ${ }^{1}$, KEIICHI MITSUYAMA ${ }^{1,2}$, HIDETOSHI TAKEDATSU $^{1}$, \\ SHINICHIRO YOSHIOKA ${ }^{1}$, HIROSHI YAMASAKI ${ }^{1}$, RYOSUKE YAMAUCHI $^{1}$, ATSUSHI MORI ${ }^{1}$, \\ TATSUYUKI KAKUMA ${ }^{3}$, OSAMU TSURUTA ${ }^{1}$ and TAKUJI TORIMURA ${ }^{1}$ \\ ${ }^{1}$ Division of Gastroenterology, Department of Medicine, ${ }^{2}$ Inflammatory Bowel Disease Center, \\ ${ }^{3}$ Department of Biostatistics Center, Kurume University School of Medicine, Kurume, Fukuoka 830-0011, Japan
}

Received May 18, 2017; Accepted October 19, 2017

DOI: $10.3892 /$ ijmm.2017.3244

\begin{abstract}
The aim of the present study was to quantify calprotectin levels using an enzyme-linked immunosorbent assay (ELISA) and a point-of-care test (POCT) in patients with inflammatory bowel disease. Overall, 113 patients with ulcerative colitis (UC; 51 men and 62 women) and 42 patients with Crohn's disease (CD; 29 men and 13 women), who were scheduled to undergo a colonoscopy, were prospectively enrolled and scored endoscopically and clinically. An additional 96 healthy, age-matched subjects served as the normal controls. Feces and blood samples from the patients with $\mathrm{UC}$ and $\mathrm{CD}$, and the normal controls were analyzed. These patients had received adequate medical treatment. The tissue distribution of calprotectin was investigated using immunohistochemistry. The fecal calprotectin levels, as measured using an ELISA, were correlated with the endoscopic and clinical disease activities and laboratory parameters, including serum levels of hemoglobin $(\mathrm{Hb})$, albumin and $\mathrm{C}$-reactive protein, and erythrocyte sedimentation rate, particularly among the patients with UC. The fecal $\mathrm{Hb}$ level was close to that of the fecal calprotectin level $(\mathrm{r}=0.57 ; \mathrm{P}<0.0001)$. The fecal calprotectin level measured using an ELISA was well-correlated with the fecal calprotectin level measured using the POCT $(\mathrm{r}=0.81$; $\mathrm{P}<0.0001)$, but was not correlated with the serum calprotectin level ( $\mathrm{r}=0.1013 ; \mathrm{P}=0.47)$. An immunohistochemical investigation revealed that patients with both UC and CD had higher neutrophil and monocyte/macrophage calprotectin-positive cell expression levels, compared with those in the normal
\end{abstract}

Correspondence to: Dr Keiichi Mitsuyama, Inflammatory Bowel Disease Center, Kurume University School of Medicine, 67 Asahi-machi, Kurume, Fukuoka 830-0011, Japan

E-mail: ibd@med.kurume-u.ac.jp

Abbreviations: ELISA, enzyme-linked immunosorbent assay; POCT, point-of-care test; IBDs, inflammatory bowel diseases; UC, ulcerative colitis; CD, Crohn's disease

Key words: calprotectin, Crohn's disease, feces, inflammatory bowel disease, enzyme-linked immunosorbent assay, point-of-care test, ulcerative colitis controls. Fecal calprotectin was considered a reliable marker for disease activity, and the assessment of fecal calprotectin via POCT showed potential as a rapid and simple measurement in clinical settings.

\section{Introduction}

Inflammatory bowel diseases (IBDs), consisting mainly of ulcerative colitis (UC) and Crohn's disease (CD), are chronic inflammatory disorders involving the gastrointestinal tract (1). To date, mucosal healing has been indicated as the therapeutic goal for IBD, as healing is associated with sustained clinical remission, reduced rates of hospitalization and surgery, and a lower incidence of colorectal cancer (2-4). To optimize the outcomes of patients with IBD, frequent monitoring is required to evaluate disease activity and treatment efficacy. Endoscopy is considered the gold standard for evaluating intestinal inflammation and mucosal healing. However, frequent endoscopic procedures are invasive, unpleasant, time-consuming and costly for patients, and they require a skilled operator and bowel preparation. Therefore, a reliable surrogate marker capable of mirroring intestinal inflammation, which can be used as a substitute for endoscopy, is required.

The fecal stream is in close contact with the intestinal mucosa and can, therefore, take up molecules serving as markers of intestinal inflammation. There are several studies concerning fecal markers for intestinal inflammation (5-8). Of these, calprotectin is the most widely used marker for evaluating the disease activity of IBD (9). Calprotectin is an abundant heterodimeric calcium-binding protein belonging to the S100 family (S100A8 and S100A9), which inhibits metalloproteinases, and has antimicrobial and pro-apoptotic activities $(10,11)$. Calprotectin is present in neutrophils, monocytes/macrophages and potentially epithelial cells, and it comprises up to $60 \%$ of the total cytosolic protein content of neutrophils. Calprotectin has several clinical advantages, including a high stability at room temperature, resistance to degradation and a homogenous distribution in stools, all of which have been described as prerequisites for biomarkers.

The use of enzyme-linked immunosorbent assay (ELISA) analyses for calprotectin has been thoroughly validated. However, the ELISA protocol is time-consuming to perform, 
and this can lead to delayed reporting of the results. As the assay also requires specialized laboratory equipment, it is predominantly used in large laboratories. To overcome these limitations, an immunochromatographic point-of-care test (POCT) for calprotectin has been developed $(12,13)$.

In the present study, the fecal calprotectin levels were measured using ELISA as the gold standard, and the correlations between these levels, endoscopic and clinical disease activities and fecal hemoglobin ( $\mathrm{Hb}$ ) were examined. In addition, the fecal calprotectin level as measured using ELISA was compared with that measured using the POCT and the serum calprotectin level, in addition to examining the immunohistochemical localization of calprotectin in the diseased intestine.

\section{Patients and methods}

Ethical consideration. The Human Ethics Committee of Kurume University School of Medicine approved the protocol in accordance with the Declaration of Helsinki. Written informed consent was obtained from each of the subjects or their parents prior to enrollment in the study.

Patients. Between January, 2014 and December, 2015, colonoscopies were performed and stool samples were collected from 113 patients with UC and 42 with $\mathrm{CD}$. The diagnoses were based on characteristic clinical, endoscopic, radiological and histological features. The patient characteristics are presented in Table I. Among the patients with UC, there were 51 men and 62 women, with a median age of 41.5 years and median disease duration of 83 months. In terms of disease distribution, 59 patients had pancolitis, 30 had left colon involvement and 24 had disease limited to the rectum. Among the patients with $\mathrm{CD}$, there were 29 men and 13 women, with a median age of 31 years and median disease duration of 54 months. The disease affected the ileum and the colon in 29 patients, the colon alone in nine patients, and the ileum alone in four patients. These patients had received adequate medical therapy. In addition, 96 healthy, age-matched subjects served as normal controls.

Endoscopic and clinical evaluations. For the evaluation of disease activity in the patients with UC, the endoscopic mucosal status was graded according to the severity of inflammation using the Rachmilewitz score (14), and clinical activity was graded using the Mayo score (15). For the patients with $\mathrm{CD}$, the endoscopic findings were graded according to the severity of inflammation using the Simple Endoscopic Score for CD (SES-CD) (16), and clinical activity was graded using the CD Activity Index (CDAI) (17).

Colonoscopy. Bowel preparation was performed using a polyethylene glycol-based or magnesium citrate-based electrolyte solution according to the standard protocol used in Kurume University Hospital in Japan. Following the clearing of colonic lavage fluid, the patients underwent a colonoscopy. Patients were excluded from the study if the colonoscopic examination was incomplete due to problems with the bowel preparation or if it was not possible to insert the colonoscope into the cecum.

Collection of stool samples. The stool samples were collected on the day of colonoscopy, or a few days prior to colonoscopy
Table I. Patient characteristics.

\begin{tabular}{|c|c|c|}
\hline Characteristics & $\begin{array}{l}\text { Ulcerative colitis } \\
\qquad(\mathrm{n}=113)\end{array}$ & $\begin{array}{c}\text { Crohn's disease } \\
(n=42)\end{array}$ \\
\hline Sex, male/female & $51 / 62$ & $29 / 13$ \\
\hline $\begin{array}{l}\text { Age, years } \\
\text { (median, IQR) }\end{array}$ & $41.5(30-57)$ & $31(22-40.75)$ \\
\hline Area involved & $\begin{array}{l}\text { Total colitis/ } \\
\text { left-side } \\
\text { colitis/proctitis } \\
59 / 30 / 24\end{array}$ & $\begin{array}{l}\text { Ileitis/ } \\
\text { ileocolitis/ } \\
\text { colitis } \\
4 / 29 / 9\end{array}$ \\
\hline $\begin{array}{l}\text { Disease duration, months } \\
\text { (median, IQR) }\end{array}$ & $83(38-173.5)$ & $54(15.5-166)$ \\
\hline \multicolumn{3}{|l|}{ Treatments } \\
\hline $\begin{array}{l}\text { 5-Aminosalicylic } \\
\text { acid }(\%)\end{array}$ & $100(87.7)$ & $33(78.6)$ \\
\hline Prednisolone (\%) & $30(26.3)$ & $3(7.1)$ \\
\hline Immunomodulator (\%) & $16(14.0)$ & $9(21.4)$ \\
\hline Leukocytapheresis (\%) & $2(1.8)$ & $1(2.4)$ \\
\hline Nutrition therapy (\%) & $3(2.6)$ & $18(42.9)$ \\
\hline $\begin{array}{l}\text { Antitumor necrosis } \\
\text { factor }(\%)\end{array}$ & $2(1.8)$ & $17(40.5)$ \\
\hline Surgery (\%) & $1(0.9)$ & $5(11.9)$ \\
\hline
\end{tabular}

and stored in a refrigerator until the day of the colonoscopy. Upon receipt in the laboratory, all stool samples were registered and stored at $-20^{\circ} \mathrm{C}$. Following thawing, the fecal samples were prepared and analyzed according to the test manufacturer's protocol (Bühlmann Laboratories AG, Schönenbuch, Switzerland). Between 40 and $120 \mathrm{mg}$ of stool was collected into the hollow cavity of the extraction tool (Smart-Prep; Bühlmann Laboratories AG), and extraction buffer in a weight/volume ratio of 1:50 was then added to the extraction tube. The sample tubes were mixed for 1 min using a vortex mixer until no large particles were present. Subsequently, $1 \mathrm{ml}$ of the homogenate was transferred to an Eppendorf tube and centrifuged for $5 \mathrm{~min}$ at 3,000 $\mathrm{x} \mathrm{g}$ at room temperature. The supernatant $(0.5 \mathrm{ml})$ was transferred to a new tube and stored at $-20^{\circ} \mathrm{C}$ until the assay.

Measurement of fecal calprotectin. Fecal calprotectin was measured using a quantitative enzyme-linked immunosorbent assay (fCAL ${ }^{\text {TM }}$ ELISA; Bühlmann Laboratories AG) according to the manufacturer's protocol $(12,18)$. The fecal calprotectin level was also measured using a quantitative rapid point-of-care test (POCT; Quantum Blue ${ }^{\circledR}$ Calprotectin; Bühlmann Laboratories AG), which uses immunochromatographic technology in a lateral flow assay system, including an easy-to-use Quantum Blue ${ }^{\circledR}$ reader. The test was performed in accordance with the manufacturer's protocol.

Measurement of fecal $\mathrm{Hb}$. Fecal $\mathrm{Hb}$ was determined using a quantitative fecal immunochemical test, as described previously (19-21). Briefly, the stool sample was collected using an OC-Hemodia sampling probe and was immediately processed 

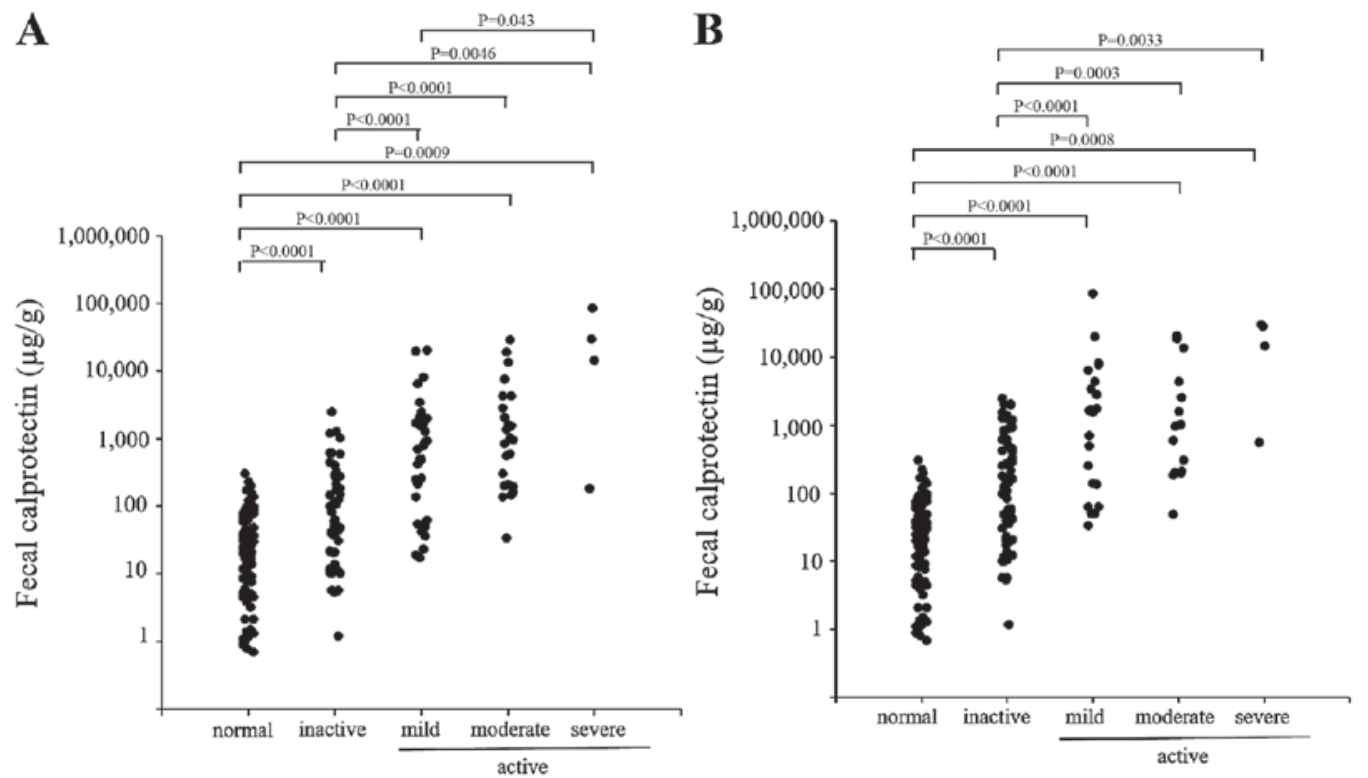

Figure 1. Fecal calprotectin levels in patients with ulcerative colitis. Fecal calprotectin levels according to (A) endoscopic disease activity as assessed using the Rachmilewitz score and (B) clinical disease activity as assessed using the Mayo score.

and examined using OC-SENSOR neo (both from Eiken Chemical, Tokyo, Japan), which can accurately measure fecal $\mathrm{Hb}$ levels between 50 and $1,000 \mathrm{ng} / \mathrm{ml}$.

Measurement of serum calprotectin. The serum calprotectin levels were quantified using an ELISA (sCAL ${ }^{\mathrm{TM}}$ ELISA; Bühlmann Laboratories AG). In brief, a blood sample ( $0.5 \mathrm{ml})$ for serum calprotectin measurements was collected in blood collection tubes containing ethylenediaminotetraacetic acid. The sample was centrifuged for $10 \mathrm{~min}$ at $10,000 \mathrm{rpm}$ and the extracted serum was collected and frozen at $-20^{\circ} \mathrm{C}$ for subsequent measurement. The serum was diluted 1:50, and $100 \mu 1$ of each sample was added to the wells of a plate and incubated at room temperature for $45 \mathrm{~min}$. The plate was then washed three times with diluted washing solution, and $100 \mu \mathrm{l}$ of monoclonal anti-calprotectin antibody conjugated with horseradish peroxidase were added and incubated for $45 \mathrm{~min}$ at room temperature. A second washing procedure was performed, $100 \mu \mathrm{l}$ of enzyme substrate solution was added to each well, and optical density was read at $450 \mathrm{~nm}$. The serum calprotectin concentration was calculated from the standards and expressed as $\mu \mathrm{g} / \mathrm{ml}$.

Determination of laboratory parameters. A blood sample was also obtained from each patient and was used to measure various laboratory parameters. The total leukocyte count, platelet count, serum levels of $\mathrm{Hb}$, albumin and C-reactive protein and erythrocyte sedimentation rate were determined by routine laboratory analysis within three days prior to or following collection of the stool sample used for calprotectin measurement.

Immunohistochemistry. To examine the expression of calprotectin using immunocytochemistry, a primary monoclonal antibody targeting calprotectin (clone MAC387; cat. no. M0747; Dako, Glostrup, Denmark) was used at a dilution of 1:1,600 (incubation time, $50 \mathrm{~min}$ ) and a secondary antibody (One-step polymer-HRP, cat. no. HK595-50K; BioGenex, Fremont, CA, USA) was used at a dilution of 1:600 (incubation time, $15 \mathrm{~min}$ ). Double staining was performed using monoclonal anti-neutrophil elastase (diluted 1:400; clone NP57, cat. no. M0752), monoclonal anti-CD68 (diluted 1:100; clone KP1, cat. no. M0814) (both from Dako) and monoclonal anti-calprotectin (incubation time, $50 \mathrm{~min}$ ). The sections were developed using 3,3'-diaminobenzidine for anti-calprotectin and alkaline phosphatase for anti-neutrophil elastase and anti-CD68. We used a Nikon Optiphot microscope (Nikon Corp., Tokyo, Japan) for visualization of staining.

Statistical analysis. The results are presented as the median and range. As calprotectin measurements were highly skewed, log-transformed values were used in data analyses. All statistical analyses were performed using the Statistical Package for the Social Sciences for Windows software 14.0 (SPSS, Inc., Chicago, IL, USA). The statistical analyses were performed using nonparametric Mann-Whitney and Kruskal-Wallis tests. Correlations between variables were estimated using the two-tailed Spearman's rank order correlation coefficient. The mean differences between the assays were calculated based on the methods described previously (22). $\mathrm{P}<0.05$ was considered to indicate a statistically significant difference.

\section{Results}

Fecal calprotectin. The individual fecal calprotectin levels of the patients with UC are shown in Fig. 1. The endoscopic disease activity was graded according to the Rachmilewitz score as either inactive, mild, moderate or severe (Fig. 1A). The fecal calprotectin levels were significantly higher among the patients with UC, compared with those among the normal controls. The fecal calprotectin level was closely correlated with the endoscopic grade, and the concentrations differed significantly among the groups. The clinical disease activity (Fig. 1B) was grouped according to the Mayo score 
A
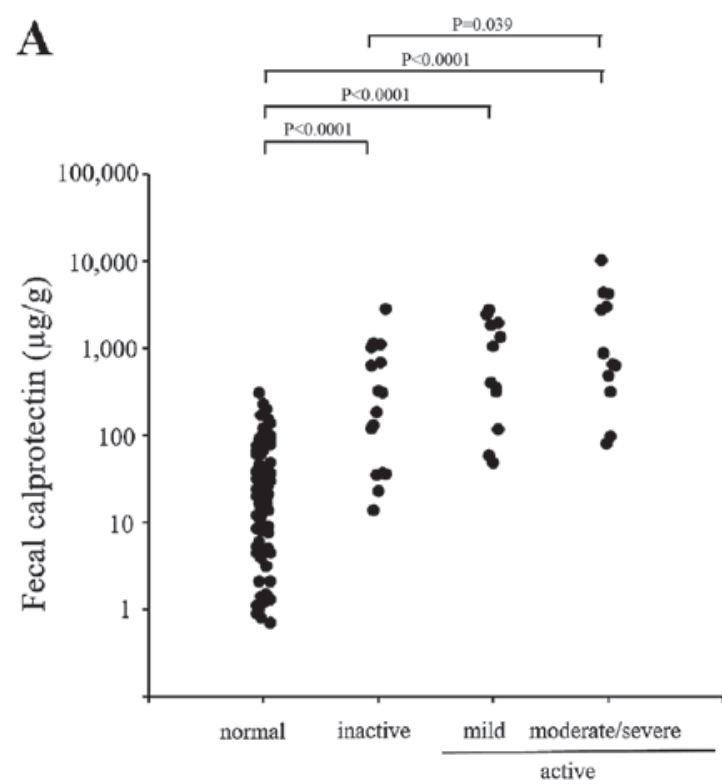

B
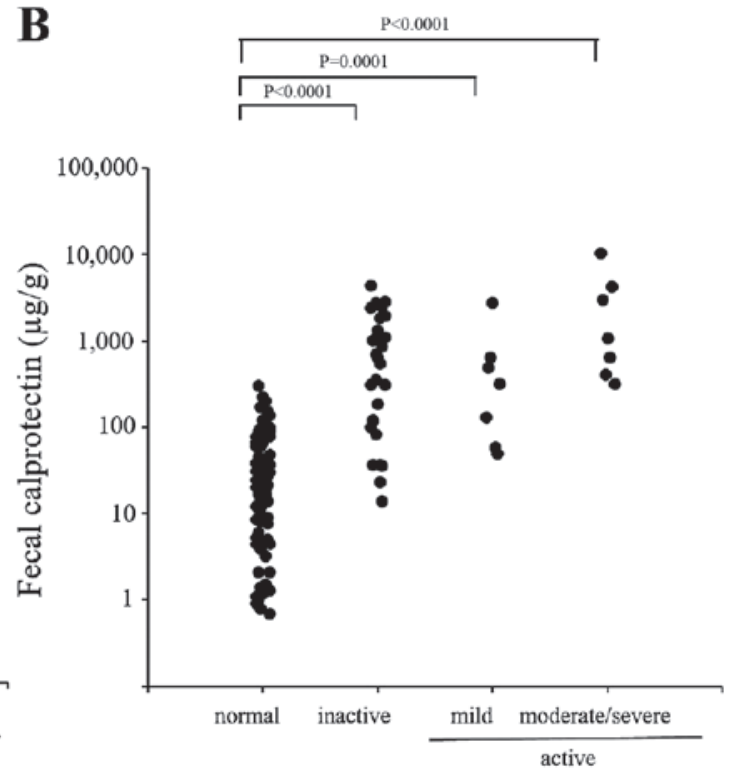

Figure 2. Fecal calprotectin levels in patients with CD. Fecal calprotectin levels according to the (A) endoscopic disease activity as assessed using the simple endoscopic score for $\mathrm{CD}$ and (B) clinical disease activity as assessed using the $\mathrm{CD}$ activity index. $\mathrm{CD}$, Crohn's disease.

A
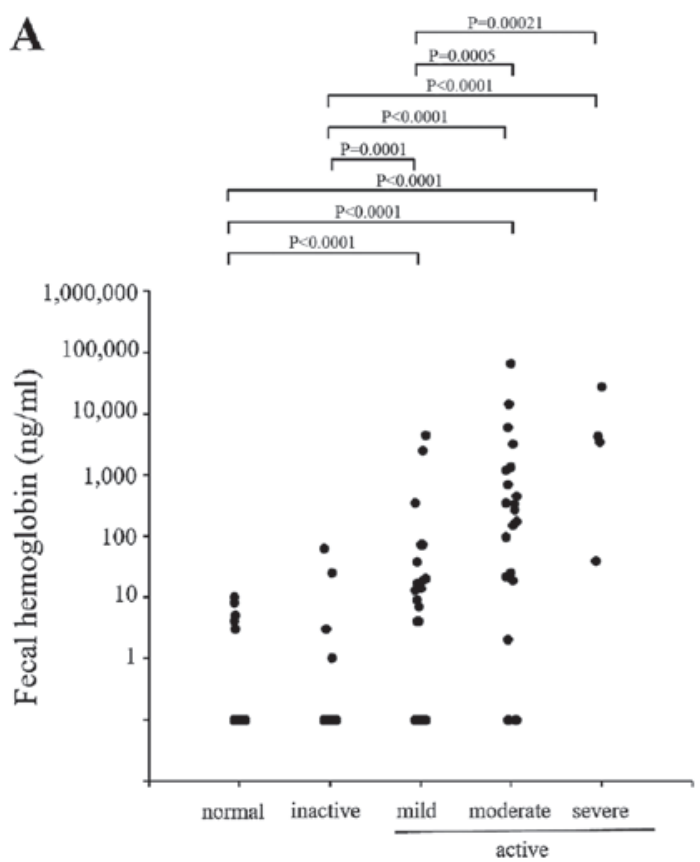

B
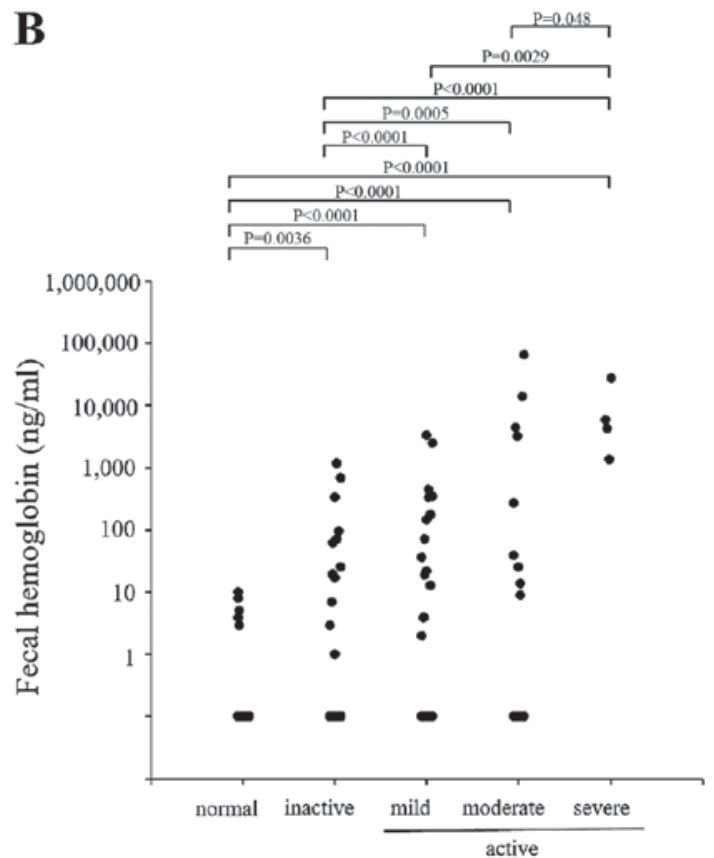

Figure 3. Fecal hemoglobin levels in patients with ulcerative colitis. Fecal hemoglobin levels according to (A) endoscopic disease activity as assessed using the Rachmilewitz score and (B) clinical disease activity as assessed using the Mayo score.

into inactive, mild, moderate or severe. A close correlation between the fecal calprotectin level and the clinical disease activity was also observed.

The individual fecal calprotectin levels in patients with $\mathrm{CD}$ are shown in Fig. 2. The endoscopic disease activity was graded according to the SES-CD into inactive, mild, moderate or severe disease (Fig. 2A), and the clinical disease activity was classified according to the CDAI into inactive, mild, moderate or severe disease(Fig. 2B). In contrast to the patients with UC, only a weak correlation was observed between the fecal calprotectin level and the endoscopic and clinical disease activities in patients with $\mathrm{CD}$.
Fecal $\mathrm{Hb}$. The fecal $\mathrm{Hb}$ levels were also measured in patients with UC (Fig. 3) and in those with CD (Fig. 4). Similar to the calprotectin results, a close association was observed between the fecal $\mathrm{Hb}$ level and the endoscopic and clinical disease activity in the patients with UC, however, only a partial correlation was observed in the patients with $\mathrm{CD}$. A significant correlation was observed between the level of fecal calprotectin and the level of fecal $\mathrm{Hb}$ in the patients with $\mathrm{UC}$ and those with $\mathrm{CD}$ (Fig. 5).

Correlation with laboratory parameters. The correlation coefficients and significance values between the fecal calprotectin or fecal $\mathrm{Hb}$ levels and the indicated laboratory parameters are 
A
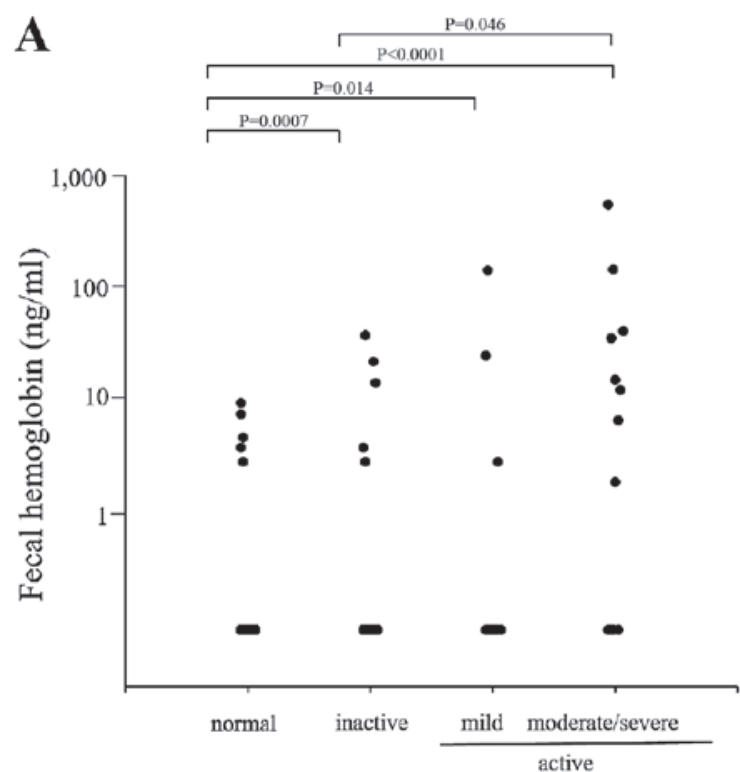

B
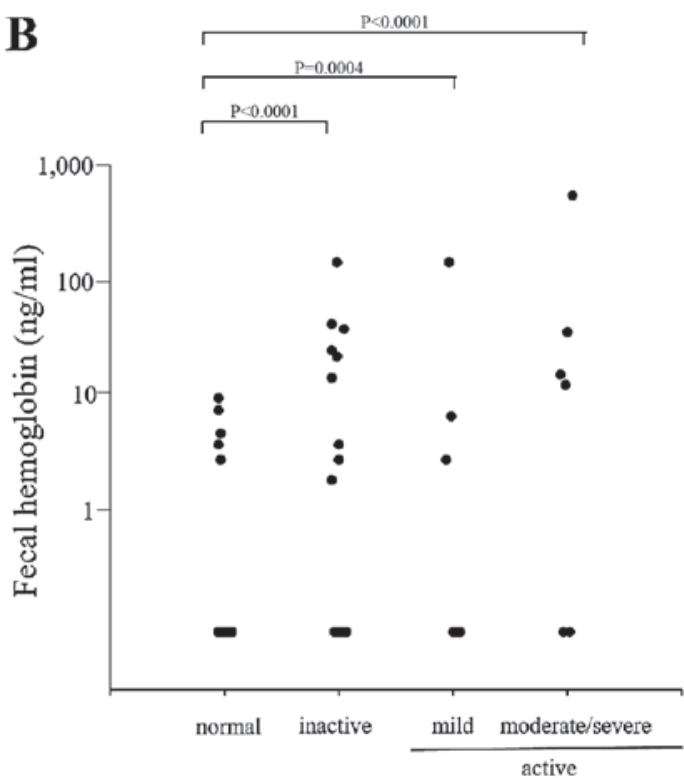

Figure 4. Fecal hemoglobin levels in patients with CD. Fecal hemoglobin levels according to (A) endoscopic disease activity as assessed using the simple endoscopic score for CD and (B) clinical disease activity as assessed using the CD activity index. CD, Crohn's disease.
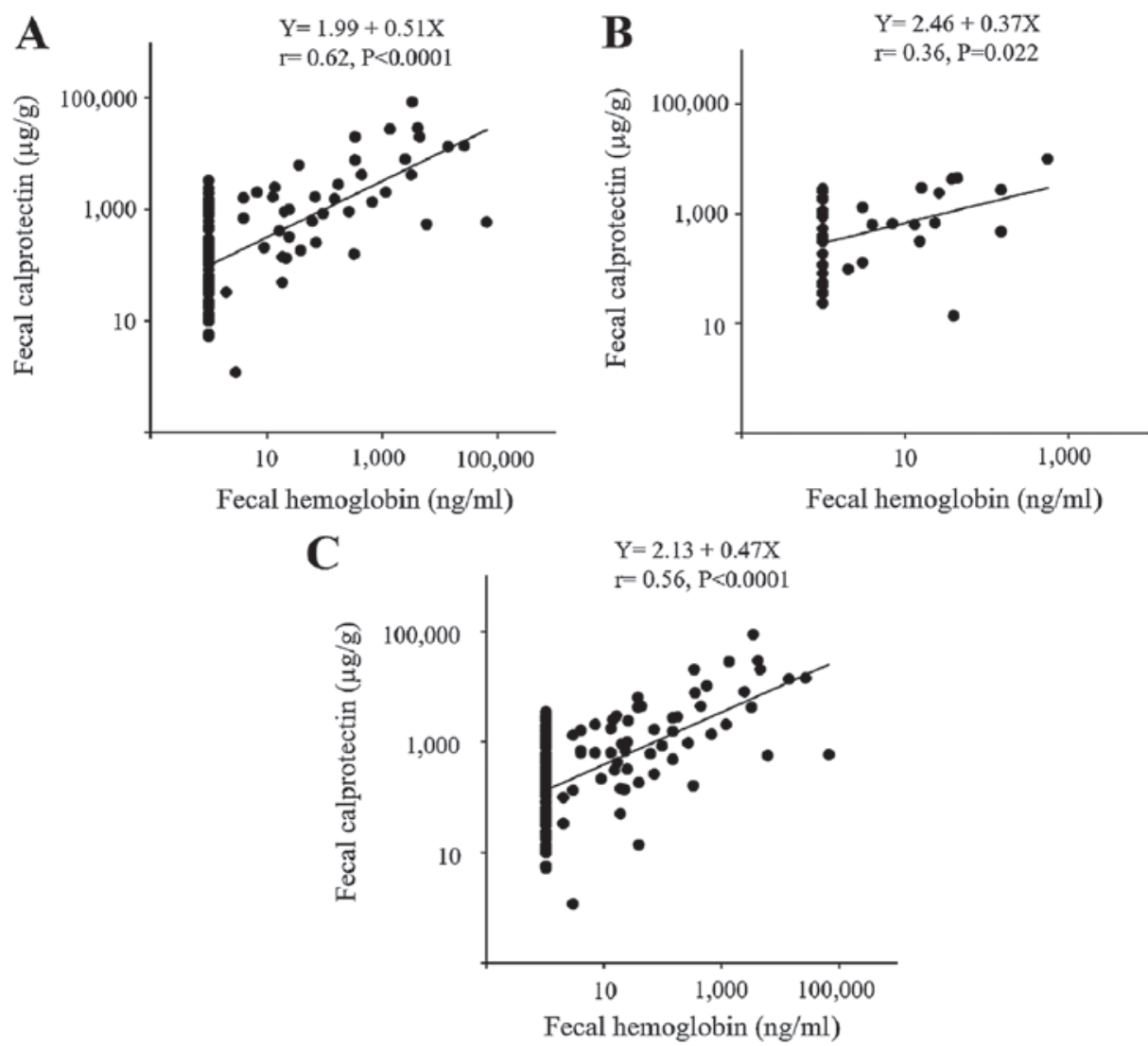

Figure 5. Correlation between the fecal calprotectin and fecal hemoglobin levels in patients with (A) UC, (B) CD and (C) inflammatory bowel disease (UC+CD). UC, ulcerative colitis; CD, Crohn's disease.

summarized in Table II. Fecal calprotectin was significantly correlated with the leukocyte count, platelet count, albumin and CRP levels and ESR in the patients with UC, and with the serum albumin level, CRP level and ESR in the patients CD. Similarly, the fecal $\mathrm{Hb}$ level was significantly correlated with the leukocyte count, albumin level, CRP level and ESR in the patients with UC, and with the platelet count, serum albumin level, CRP level and ESR in the patients with CD.

Serial measurements of fecal calprotectin. The serial changes in fecal calprotectin and other parameters within the same individual are shown in Fig. 6. Of note, decreasing concentrations 
Table II. Correlation coefficients and significance of differences between fecal markers and laboratory parameters in patients with UC or CD.

\begin{tabular}{|c|c|c|c|c|c|c|c|c|}
\hline & \multicolumn{4}{|c|}{ Fecal calprotectin } & \multicolumn{4}{|c|}{ Fecal hemoglobin } \\
\hline & \multicolumn{2}{|c|}{$\mathrm{UC}(\mathrm{n}=113)$} & \multicolumn{2}{|c|}{$\mathrm{CD}(\mathrm{n}=42)$} & \multicolumn{2}{|c|}{$\mathrm{UC}(\mathrm{n}=113)$} & \multicolumn{2}{|c|}{$\mathrm{CD}(\mathrm{n}=42)$} \\
\hline & R-value & P-value & $\mathrm{R}$-value & P-value & $\mathrm{R}$-value & $\mathrm{P}$-value & R-value & P-value \\
\hline Leukocyte $(\mu \mathrm{l})$ & 0.27 & 0.004 & -0.01 & 0.937 & 0.24 & 0.011 & -0.09 & 0.562 \\
\hline Platelet $\left(\times 10^{4} / \mu 1\right)$ & 0.25 & 0.007 & 0.17 & 0.291 & 0.05 & 0.575 & 0.41 & 0.008 \\
\hline Hemoglobin $(\mathrm{g} / \mathrm{dl})$ & -0.13 & 0.180 & -0.16 & 0.311 & -0.18 & 0.059 & -0.27 & 0.088 \\
\hline Albumin (g/dl) & -0.45 & $<.001$ & -0.27 & 0.082 & -0.56 & $<.001$ & -0.44 & 0.004 \\
\hline CRP (mg/dl) & 0.25 & 0.001 & 0.41 & 0.007 & 0.42 & $<.001$ & 0.46 & 0.002 \\
\hline ESR $1 \mathrm{~h}(/ \mathrm{mm})$ & 0.21 & 0.032 & 0.32 & 0.038 & 0.26 & 0.007 & 0.42 & 0.006 \\
\hline
\end{tabular}

CRP, C-reactive protein; ESR, erythrocyte sedimentation rate; UC, ulcerative colitis; CD, Crohn's disease.
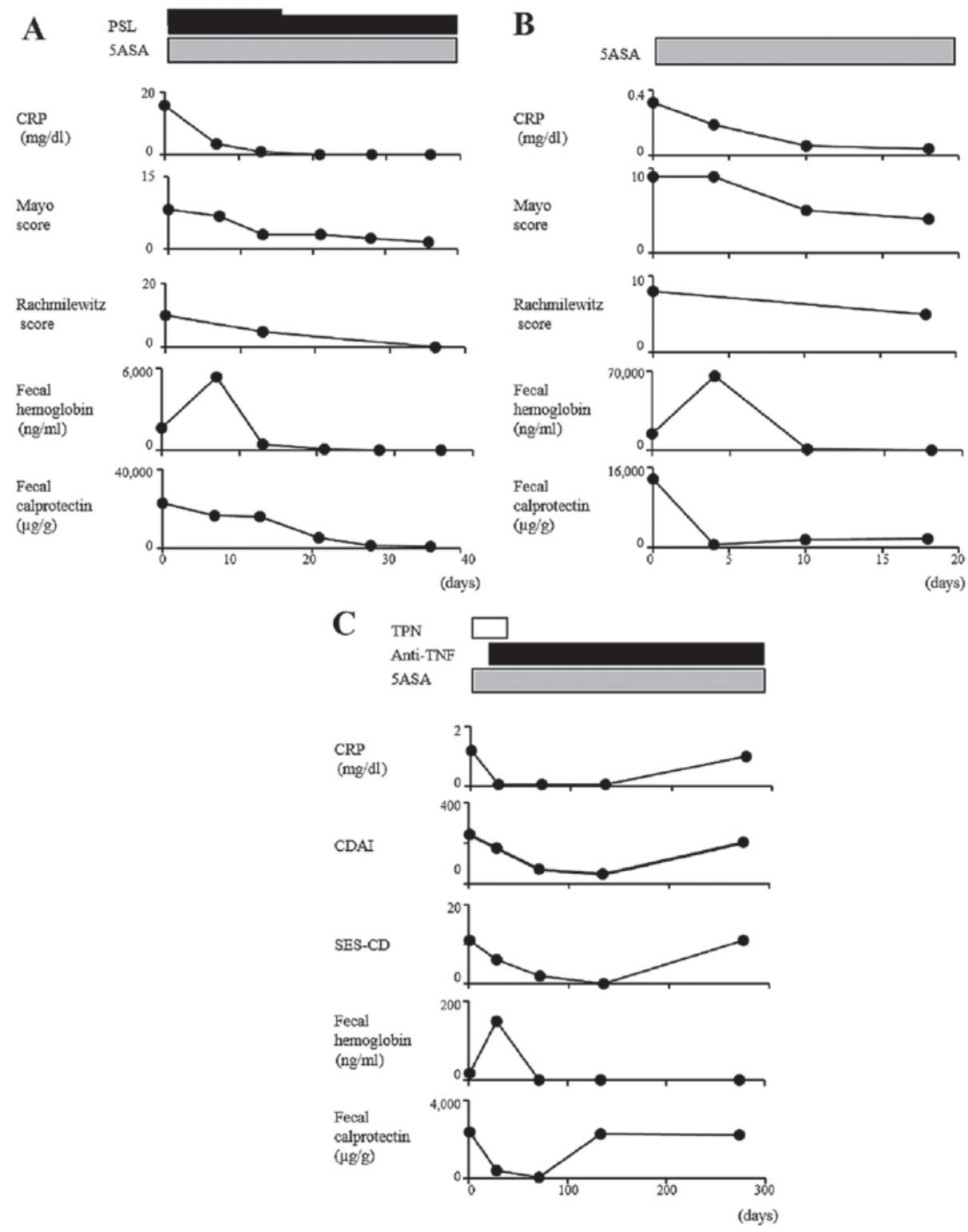

Figure 6. Time-courses for fecal calprotectin levels and other inflammatory parameters in three patients with inflammatory bowel disease. (A) Twenty-four-year male patient with UC involving the entire colon; (B) 26-year male patient with UC involving the entire colon; (C) 21-year female patient with CD involving the small and large bowel. 5ASA, 5-aminosalicylic acid; PSL, prednisolone; anti-TNF- $\alpha$, antitumor necrosis factor- $\alpha$ antibody; TPN, total parenteral nutrition; CRP, C-reactive protein; CDAI, CD activity index; SES-CD, Simple Endoscopic Score for CD; UC, ulcerative colitis; CD, Crohn's disease. 

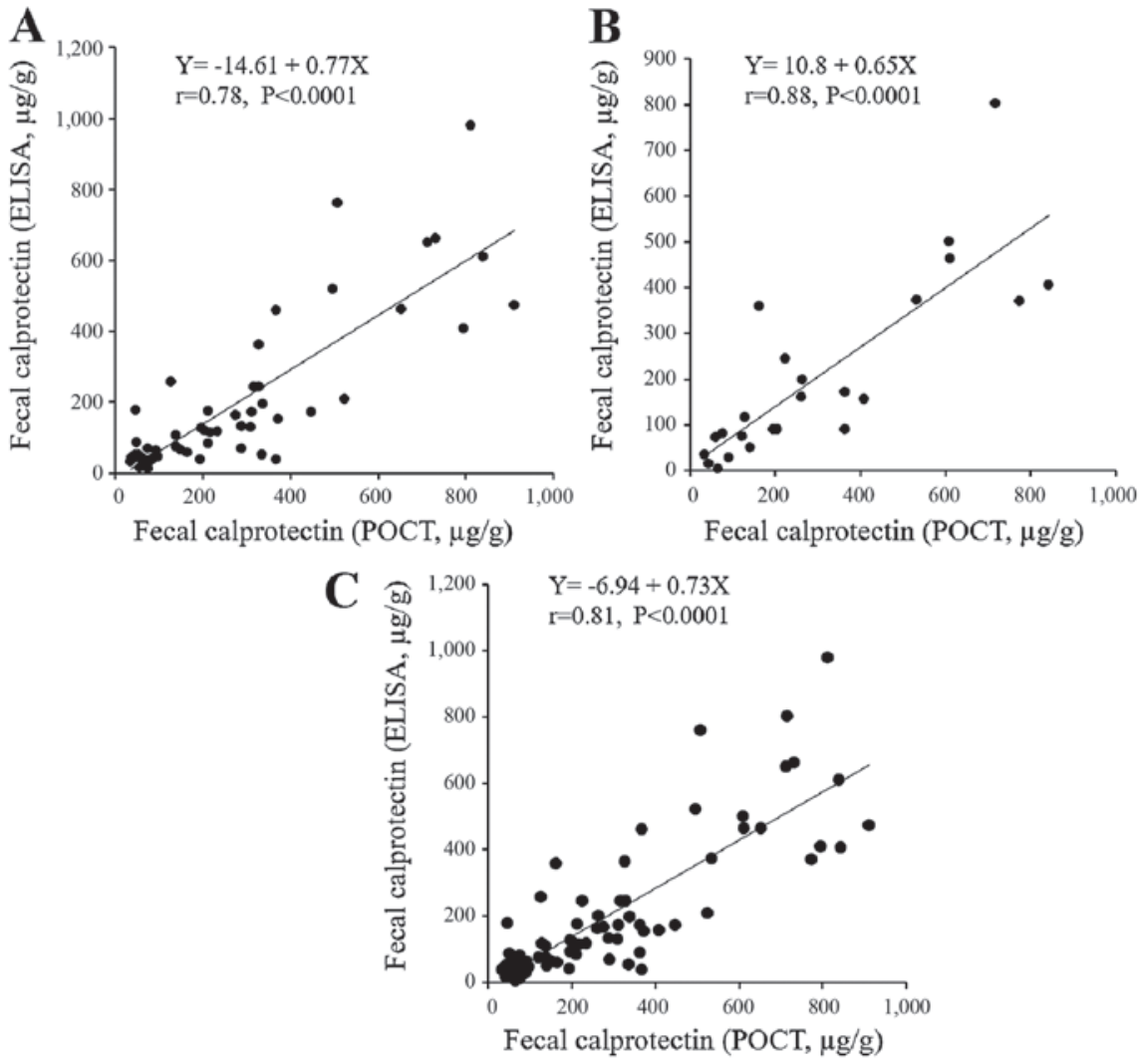

Figure 7. Correlations between fecal calprotectin levels. ELISA and a POCT were used to measure correlations between fecal calprotectin levels in patients with (A) UC, (B) CD and (C) inflammatory bowel disease (UC+CD). ELISA, enzyme-linked immunosorbent assay; POCT, point-of-care test; UC, ulcerative colitis; $\mathrm{CD}$, Crohn's disease.

of fecal calprotectin were consistently found as the disease began to abate, regardless of the treatment modality, and these concentrations remained at lower levels when stable remission had been achieved.

POCT. The ELISA results were then compared with those of a quantitative, rapid POCT performed simultaneously to measure the fecal calprotectin levels (Fig. 7). Stool samples were available from 56 patients with UC and from 24 patients with $\mathrm{CD}$. Of note, the correlation between the results of the two methods was high for the patients with UC and those with CD. The agreement between the two methods was asessed using the Bland-Altman method (22). As only six of 80 paired data $(7.5 \%)$ were outside the limit of agreement, the measurements obtained from the rapid POCT were considered to show a clinically acceptable level of agreement with ELISA (Fig. 8).

Association between serum and fecal calprotectin. The correlation between the fecal and serum calprotectin levels were also analyzed using an ELISA (Fig. 9). The samples were analyzed in 41 patients with UC and in 13 patients with CD. No statistical correlation was observed between the serum and fecal calprotectin levels for either the UC or CD groups of patients. Of note, there was a mild but statistically significant correlation between the serum calprotectin and CRP levels in the patients with UC, but not in the patients with CD (Fig. 10).

Immunocytochemistry. Immunohistochemical staining was performed using colon tissue specimens from the patients with UC and CD, and increased numbers of calprotectinpositive cells, including inflammatory leukocytes, were found in the colonic mucosa, compared with the tissues from the normal controls (Fig. 11A-C). In addition, to define the types of leukocytes responsible for expressing calprotectin, double immunohistochemistry for calprotectin and neutrophil elastase-positive neutrophils (Fig. 11D) or CD68-positive macrophages (Fig. 11E) were performed in sequential sections from the same sample of an UC specimen. The results showed that the colonic mucosa specimens from the patients with UC and CD had higher levels of neutrophil and monocyte calprotectin-positive cells, compared with those observed in the normal control specimens.

\section{Discussion}

Endoscopy is considered the gold standard for the diagnosis and follow-up of patients with IBD. However, a less invasive approach is now being sought for the management of these patients. Fecal calprotectin is the most widely used marker for IBD for evaluating intestinal inflammation and mucosal healing. The present study focused on the detection of calprotectin in stool and serum samples, and examined its immunohistochemical localization in colon specimens.

In patients with $\mathrm{UC}$, it was found that the fecal calprotectin level increased significantly, and was closely correlated with endoscopic and clinical disease activities and laboratory parameters, particularly in patients with UC; these results were consistent with previously published data (9,23-25). Although 


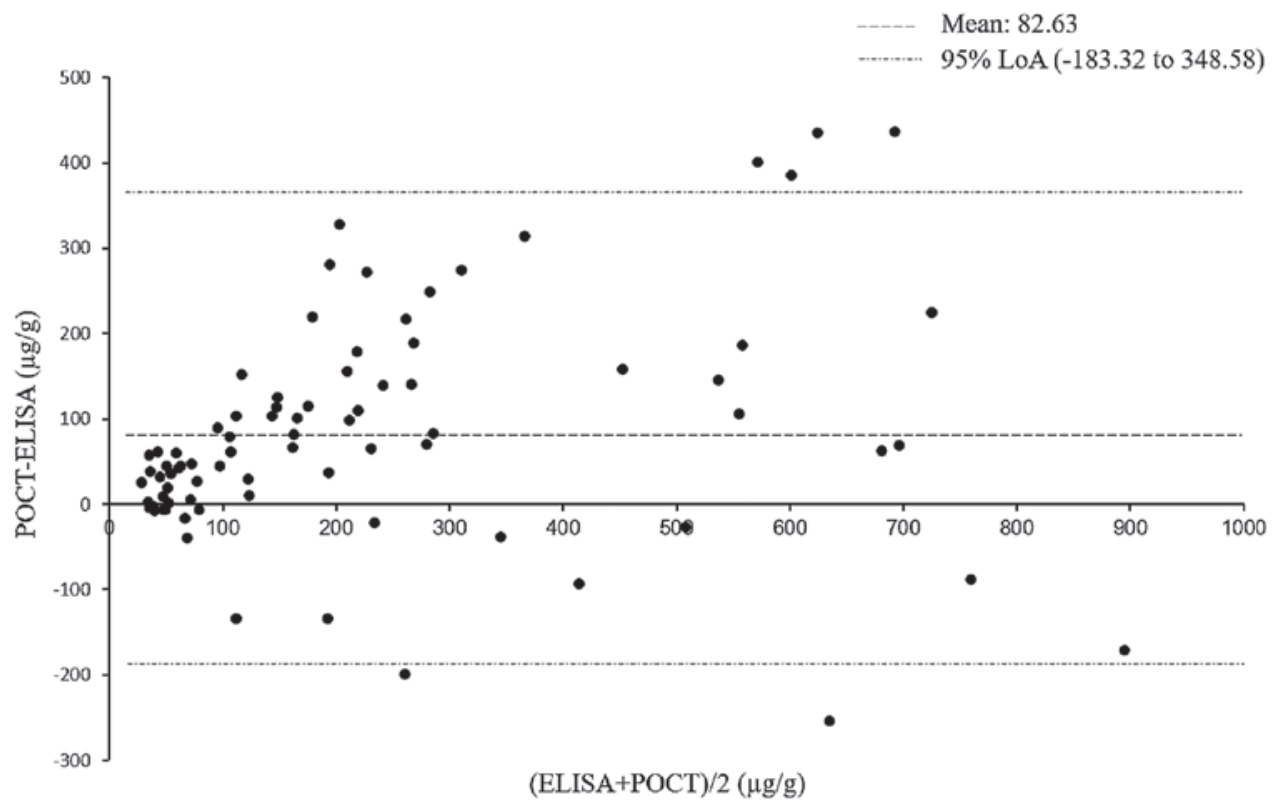

Figure 8. Mean differences in fecal calprotectin levels between ELISA and POCT values in 80 patients with inflammatory bowel disease, including 56 patients with ulcerative colitis and 24 patients with Crohn's disease. The differences between the ELISA and POCT values for each of the patients are plotted against the mean of the two measurements; the LoA, defined as the mean \pm 2 standard deviations of the difference, are shown. ELISA, enzyme-linked immunosorbent assay; POCT, point-of-care test; LoA, limit of agreement.

A

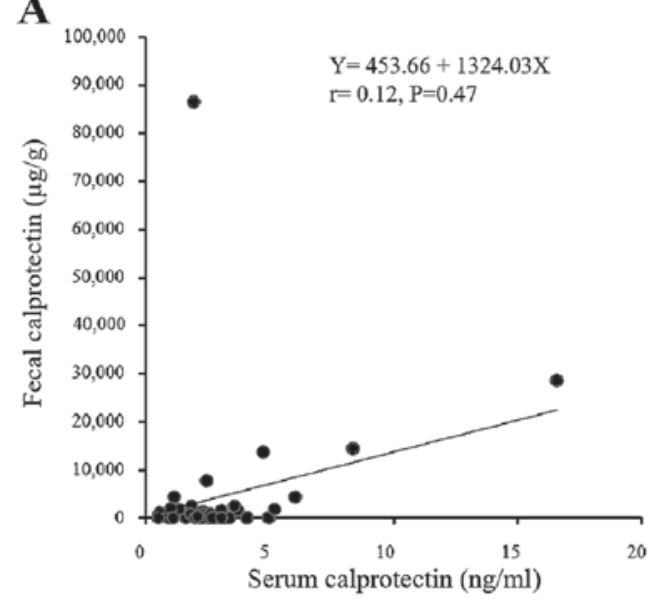

C

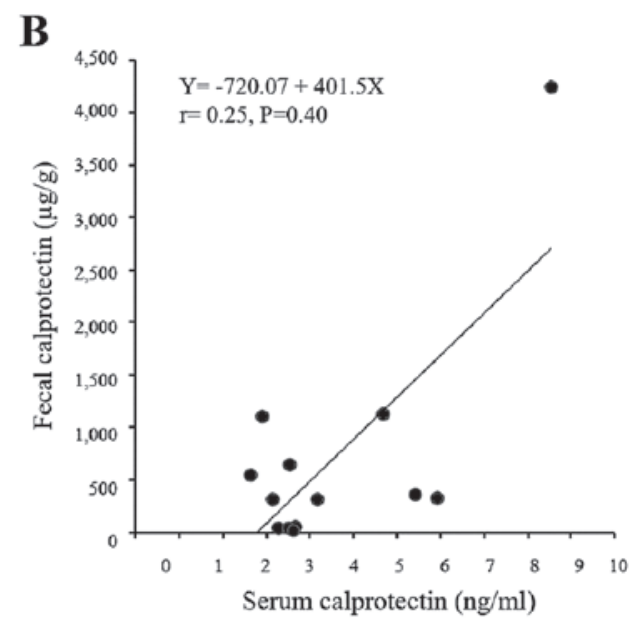

$\mathrm{Y}=18.2+1122.2 \mathrm{X}$

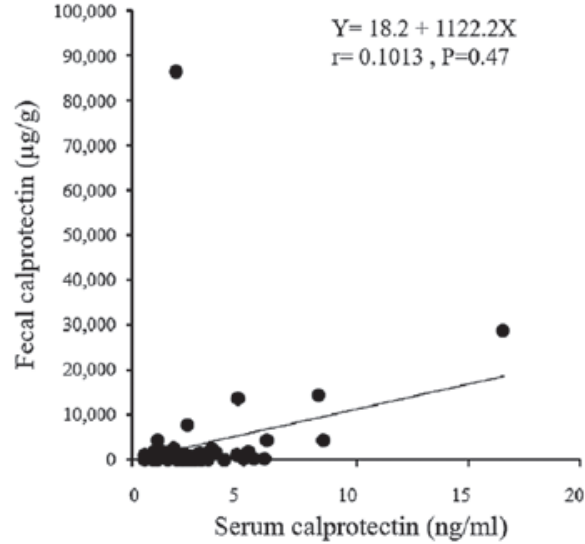

Figure 9. Correlation between fecal and serum calprotectin levels. Correlation between fecal and serum calprotectin levels were measured using an enzyme-linked immunosorbent assay in patients with (A) UC, (B) CD and (C) inflammatory bowel disease (UC+CD). UC, ulcerative colitis; CD, Crohn's disease.

the data obtained in the present study showed close correlations between the fecal calprotectin level and laboratory parameters, the fecal calprotectin level has been consistently shown to be superior to laboratory parameters, due to its high specificity 

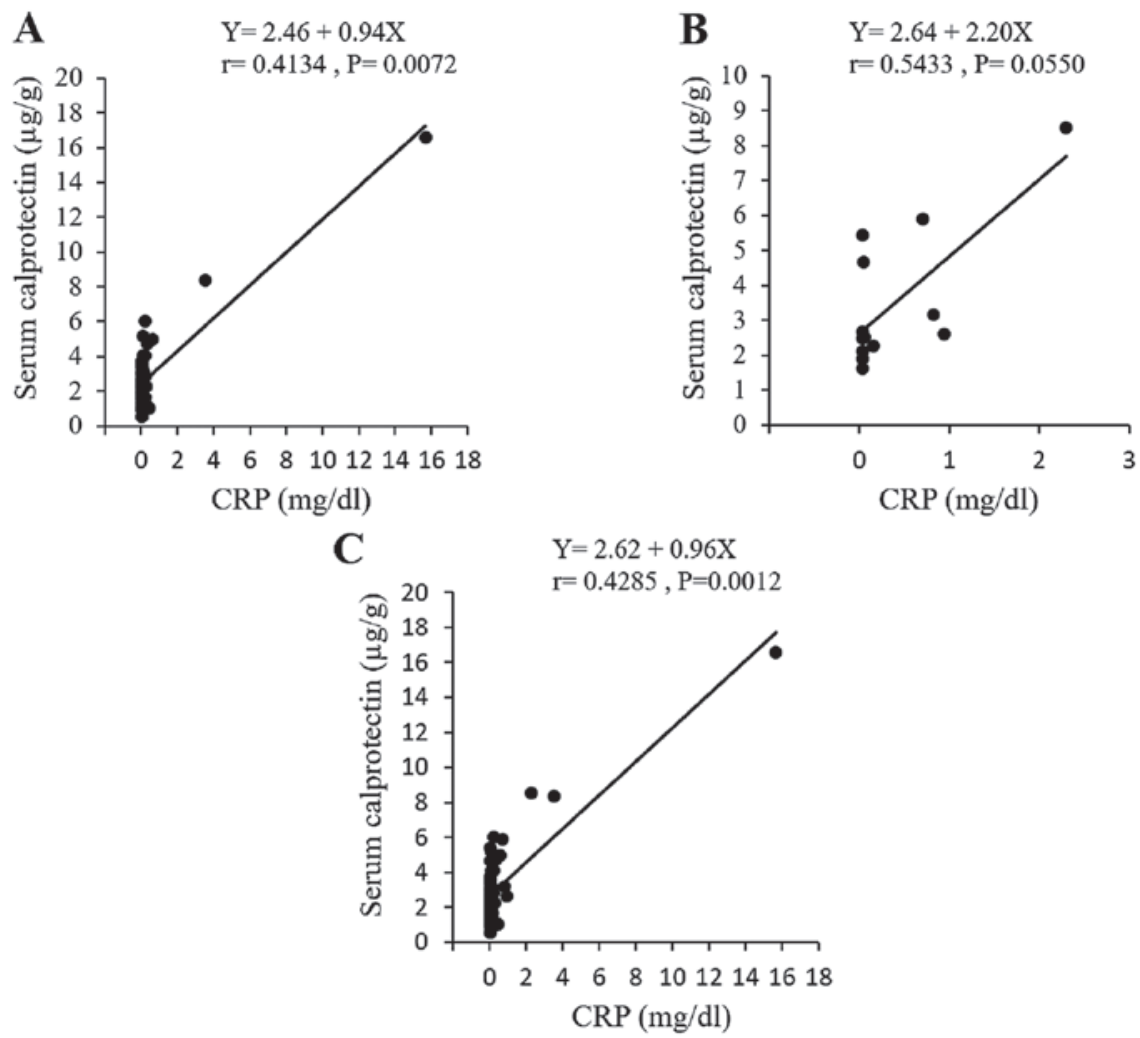

Figure 10. Correlation between serum concentrations of calprotectin and CRP in patients with (A) UC, (B) CD and (C) inflammatory bowel disease (UC+CD). UC, ulcerative colitis; CD, Crohn's disease.
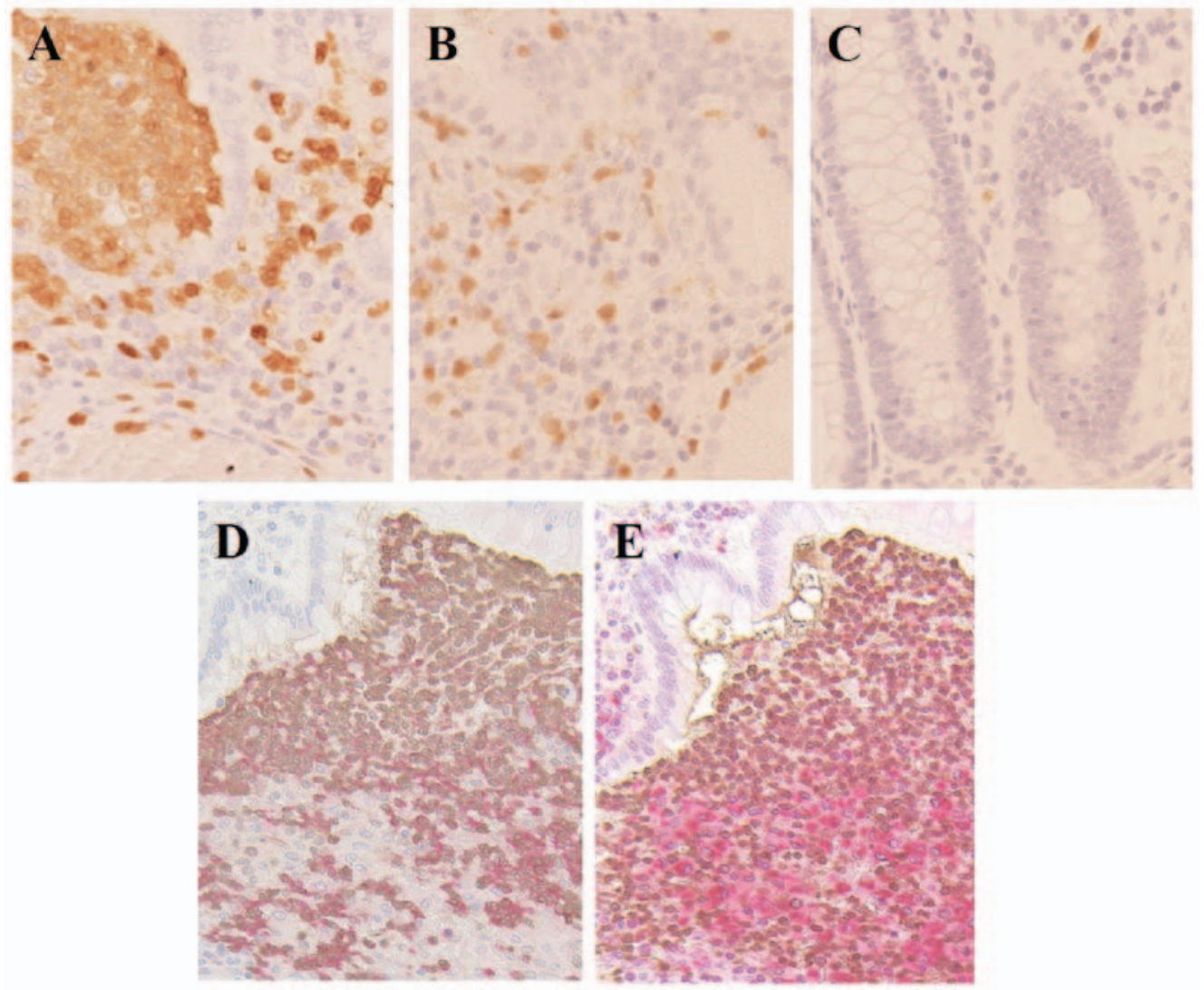

Figure 11. Immunohistochemistry for the detection of calprotectin-stained cells in colonic samples. Samples from a patient with (A) UC, a patient with (B) Crohn's disease and a (C) normal subject. (D) Double staining of colonic tissue specimens from a patient with UC showed calprotectin-positive cells (brown), anti-neutrophil elastase stain-positive neutrophils (red) and double-positive cells (purple). (E) Double staining of colonic tissue specimens from a patient with UC showed calprotectin-positive cells (brown), anti-CD68-staining-positive macrophages (brown), and double-positive cells (purple). These tissue sections revealed that neutrophils and certain macrophage populations expressed calprotectin. UC, ulcerative colitis. Original magnification, x20. 
for the assessment of intestinal inflammation. In patients with $\mathrm{CD}$, the fecal calprotectin level also increased, however, its correlation with endoscopic and clinical disease activities and laboratory markers was relatively weak, compared with the correlations observed for patients with UC, although the number of patients with CD was relatively small. This difference may be explained, in part, by the characteristic features of $\mathrm{CD}$, including the focality of the disease and its uneven, deeper tissue involvement within the intestinal wall. This leads to an unpredictable level of release from the mucosa, and possibly weakens the correlation between the fecal calprotectin level and disease activity. At present, the use of fecal calprotectin levels for estimating CD activity is controversial (26-29). Although a correlation between elevated calprotectin levels and colonic inflammation has been confirmed repeatedly, correlation for the small bowel is less well established. The endoscopic assessment of all segments, including the small bowel and colon, may be required for assessing the disease activity in patients with CD. Taken together, the results of the present study suggested that the fecal calprotectin level is a reliable marker for assessing IBD disease activity, however, it may be more useful for evaluating disease activity in patients with UC than in those with CD.

Using the same samples, the present study concurrently measured the fecal $\mathrm{Hb}$ levels using an immunoassay as an alternate fecal marker for intestinal inflammation. Evidence on the correlation between fecal $\mathrm{Hb}$ levels and disease activity remains limited (30). The present study found that the level of fecal $\mathrm{Hb}$ was close to that of fecal calprotectin, particularly in patients with UC, which was in agreement with the results of a previous study by Nakarai et al, showing that fecal $\mathrm{Hb}$ and calprotectin levels were equally capable of predicting mucosal healing (19). The most important difference between fecal $\mathrm{Hb}$ and calprotectin is that fecal $\mathrm{Hb}$ is a marker of intestinal bleeding, whereas calprotectin is specific to activated mucosal leukocytes, which are critical in the underlying pathophysiology of IBD. Although further investigations are required, the performance of fecal $\mathrm{Hb}$ was comparable to that of fecal calprotectin in patients with UC, suggesting its applicability as a novel surrogate marker of inflammation. In contrast to the results for the patients with UC, the fecal $\mathrm{Hb}$ level appeared to be less sensitive in the patients with $\mathrm{CD}$, which was consistent with the findings of a previous study (21). Fecal $\mathrm{Hb}$ tests were originally developed as a marker for colorectal cancer, rather than small bowel disease, and the use of fecal $\mathrm{Hb}$ as a marker for $\mathrm{CD}$ requires further investigation. At present, the reason for the positive correlation between fecal $\mathrm{Hb}$ and calprotectin concentrations observed in the present study remains speculative. However, the increased permeability observed in chronic mucosal inflammatory conditions (31) may be partly responsible for this association.

One of the situations in which the measurement of fecal calprotectin is likely to be useful is in evaluating the response to treatment. However, few follow-up studies have examined fecal calprotectin levels in patients with IBD, and the serial changes in fecal calprotectin levels in the same individual remains to be fully elucidated. Although the present study was largely crosssectional, follow-up examinations were performed for a small number of patients, and a change in calprotectin paralleling that of disease activity was observed throughout the course of the disease, further supporting the potential use of this marker for monitoring disease activity. A large-scale, longitudinal study, examining patients with IBD, is required.

The present study also examined the reliability of POCT measurements, compared with those obtained using ELISA, which is the gold standard test for measuring fecal calprotectin levels. ELISA is highly accurate, however, it must be performed in a laboratory and requires the collection of multiple samples; POCT is an easy and rapid technique, which also provides quantitative results but is more widely available and can be performed for individual samples $(12,13)$. The data obtained in the present study showed a high level of correlation between the two techniques, suggesting that POCT may be used as a reliable alternative to ELISA for evaluating disease activity and for the follow-up of patients with IBD. Further comprehensive investigations are required to compare the abilities of these parameters to accurately reflect disease activity in patients with IBD.

High serum calprotectin levels have been described in patients with systemic lupus erythematosus, anti-neutrophil cytoplasmic antibody (ANCA)-associated vasculitis, rheumatoid arthritis, juvenile idiopathic arthritis, Kawasaki disease and renal allograft rejection (32-38). At present, few studies have been performed on serum calprotectin in IBD, and the value of this parameter for estimating disease activity is controversial $(39,40)$. The present study is the first, to the best of our knowledge, to measure serum and fecal calprotectin levels concurrently. It was found that serum calprotectin levels were correlated with the serum CRP levels, particularly in patients with UC, but that the serum calprotectin levels were not correlated with the fecal calprotectin levels. In ANCA-associated vasculitis, patients have been shown to exhibit higher cell-surface calprotectin expression levels in circulating neutrophils and monocytes, as assessed using flow cytometry, in association with increases in serum calprotectin levels (34). Accordingly, serum calprotectin is considered to be derived predominantly from circulating leukocytes, and not diseased intestine; therefore, the serum calprotectin level may actually reflect systemic inflammation, rather than intestinal inflammation. The clinical application of serum calprotectin warrants further validation in large cohorts.

In the context of IBD, calprotectin may be released at sites of intestinal inflammation, leading to an increase in the fecal calprotectin level. To confirm the cellular source in the intestine, immunohistochemistry was performed in the present study. It was found that calprotectin was expressed in neutrophils and monocytes/macrophages, and the excess calprotectin released from these cell types in response to inflammatory stimuli may spill into the gut lumen (6). In addition to being an inflammatory marker, calprotectin exerts several effects, suggesting that it may have a more direct pathogenic role in IBD. Calprotectin-induced stimulation of monocytes/macrophages, acting through Toll-like recepror-4, activates nuclear factor- $\kappa \mathrm{B}$ and other transcription factors, leading to the increased production of metalloproteinases (41) and proinflammatory cytokines (42), in addition to stimulating interleukin-17-producing T cells (43), which have been implicated in IBD. Of note, a previous study using calprotectin-knockout mice showed that calprotectin was critical for the development of glomerulonephritis and that it promoted inflammatory leukocyte-renal cell interactions (44). Taken 
together, these findings suggest that calprotectin, which is derived predominantly from activated neutrophils and monocytes/macrophages, may contribute to the activation of innate immunity and be involved in the pathophysiology of IBD.

The present study had several limitations. Firstly, although a prospective design was used, the study was performed at a single center and involved a limited number of patients, particularly those with CD. Secondly, the endoscopic disease activity was evaluated for the region with the most severe inflammation, whereas the disease extent and location were not considered. In patients with $\mathrm{CD}$, disease activity may exist in the upper gastrointestinal tract or in other segments of the small bowel, which cannot be reached when performing an endoscopy. In addition, the calprotectin concentration may depend on the sampling position within the stool, although the distribution of calprotectin within a single stool sample appears to be homogeneous. Finally, although clinical studies, including the present study, have demonstrated that fecal calprotectin is correlated with endoscopic disease activity, whether the normalization of fecal calprotectin levels reflects mucosal healing in IBD, which is an important treatment target, remains a topic of debate. No confirmed definition of mucosal healing exists at present. In future investigations, histologic findings require consideration in addition to endoscopic findings to enable the precise evaluation of disease activity.

Taken together, the data obtained in the present study suggested that fecal calprotectin, which is derived predominantly from neutrophils and monocytes/macrophages, is a reliable marker for the noninvasive monitoring of disease activity, particularly in patients with UC. Fecal calprotectin for POCT offers potential as a rapid and simple measurement in clinical settings.

\section{Acknowledgements}

This study was supported partly by a Grant-in-Aid from the Ministry of Science and Education (grant no. 25460964), and by the Health and Labour Sciences Research Grants for Research on Intractable Diseases from the Ministry of Health, Labour and Welfare of Japan.

\section{References}

1. Strober W, Fuss I and Mannon P: The fundamental basis of inflammatory bowel disease. J Clin Invest 117: 514-521, 2007.

2. Pineton de Chambrun G, Peyrin-Biroulet L, Lémann M and Colombel JF: Clinical implications of mucosal healing for the management of IBD. Nat Rev Gastroenterol Hepatol 7: 15-29, 2010.

3. Baert F, Moortgat L, Van Assche G, Caenepeel P, Vergauwe P, De Vos M, Stokkers P, Hommes D, Rutgeerts P, Vermeire S, et al: Mucosal healing predicts sustained clinical remission in patients with early-stage Crohn's disease. Gastroenterology 138: 463-468

4. Frøslie KF, Jahnsen J, Moum BA, Vatn MH and Group I; IBSEN Group: Mucosal healing in inflammatory bowel disease: Results from a Norwegian population-based cohort. Gastroenterology 133 : 412-422, 2007

5. Sands BE: Biomarkers of inflammation in inflammatory bowel disease. Gastroenterology 149: 1275-1285.e1272, 2015.

6. Foell D, Wittkowski H and Roth J: Monitoring disease activity by stool analyses: From occult blood to molecular markers of intestinal inflammation and damage. Gut 58: 859-868, 2009.

7. Kopylov U, Rosenfeld G, Bressler B and Seidman E: Clinical utility of fecal biomarkers for the diagnosis and management of inflammatory bowel disease. Inflamm Bowel Dis 20: 742-756, 2014.
8. Lehmann FS, Burri $\mathrm{E}$ and Beglinger $\mathrm{C}$ : The role and utility of faecal markers in inflammatory bowel disease. Therap Adv Gastroenterol 8: 23-36, 2015.

9. Schoepfer AM, Beglinger C, Straumann A, Safroneeva E, Romero Y, Armstrong D, Schmidt C, Trummler M, Pittet V and Vavricka SR: Fecal calprotectin more accurately reflects endoscopic activity of ulcerative colitis than the Lichtiger Index, C-reactive protein, platelets, hemoglobin, and blood leukocytes. Inflamm Bowel Dis 19: 332-341, 2013.

10. Johne B, Fagerhol MK, Lyberg T, Prydz H, Brandtzaeg P, Naess-Andresen CF and Dale I: Functional and clinical aspects of the myelomonocyte protein calprotectin. Mol Pathol 50: 113-123, 1997.

11. Steinbakk M, Naess-Andresen CF, Lingaas E, Dale I, Brandtzaeg P and Fagerhol MK: Antimicrobial actions of calcium binding leucocyte L1 protein, calprotectin. Lancet 336: 763-765, 1990.

12. Coorevits L, Baert FJ and Vanpoucke HJ: Faecal calprotectin: Comparative study of the Quantum Blue rapid test and an established ELISA method. Clin Chem Lab Med 51: 825-831, 2013.

13. Rogler G, Aldeguer X, Kruis W, Lasson A, Mittmann U, Nally K, Peyrin-Biroulet L, Schoepfer A, Vatn M, Vavricka S, et al: Concept for a rapid point-of-care calprotectin diagnostic test for diagnosis and disease activity monitoring in patients with inflammatory bowel disease: Expert clinical opinion. J Crohn's Colitis 7: 670-677, 2013.

14. Rachmilewitz D: Coated mesalazine (5-aminosalicylic acid) versus sulphasalazine in the treatment of active ulcerative colitis: A randomised trial. BMJ 298: 82-86, 1989.

15. Schroeder KW, Tremaine WJ and Ilstrup DM: Coated oral 5-aminosalicylic acid therapy for mildly to moderately active ulcerative colitis. A randomized study. N Engl J Med 317: 1625-1629, 1987.

16. Daperno M, D'Haens G, Van Assche G, Baert F, Bulois P, Maunoury V, Sostegni R, Rocca R, Pera A and Gevers A: Development and validation of a new, simplified endoscopic activity score for Crohn's disease: The SES-CD. Gastrointest Endosc 60: 505-512, 2004.

17. Best WR, Becktel JM and Singleton JW: Rederived values of the eight coefficients of the Crohn's Disease Activity Index (CDAI). Gastroenterology 77: 843-846, 1979.

18. Oyaert M, Trouvé C, Baert F, De Smet D, Langlois M and Vanpoucke H: Comparison of two immunoassays for measurement of faecal calprotectin in detection of inflammatory bowel disease: (pre)-analytical and diagnostic performance characteristics. Clin Chem Lab Med 52: 391-397, 2014.

19. Nakarai A, Kato J, Hiraoka S, Kuriyama M, Akita M, Hirakawa T, Okada $\mathrm{H}$ and Yamamoto K: Evaluation of mucosal healing of ulcerative colitis by a quantitative fecal immunochemical test. Am J Gastroenterol 108: 83-89, 2013.

20. Takashima S, Kato J, Hiraoka S, Nakarai A, Takei D, Inokuchi T, Sugihara Y, Takahara M, Harada K, Okada H, et al: Evaluation of mucosal healing in ulcerative colitis by fecal calprotectin vs. fecal immunochemical test. Am J Gastroenterol 110: 873-880, 2015.

21. Inokuchi T, Kato J, Hiraoka S, Takashima S, Nakarai A, Takei D, Sugihara Y, Takahara M, Kawano S, Harada K, et al: Fecal immunochemical test versus fecal calprotectin for prediction of mucosal healing in Crohn's disease. Inflamm Bowel Dis 22: 1078-1085, 2016.

22. Bland JM and Altman DG: Statistical methods for assessing agreement between two methods of clinical measurement. Lancet 1: 307-310, 1986.

23. Langhorst J, Elsenbruch S, Koelzer J, Rueffer A, Michalsen A and Dobos GJ: Noninvasive markers in the assessment of intestinal inflammation in inflammatory bowel diseases: Performance of fecal lactoferrin, calprotectin, and PMN-elastase, CRP, and clinical indices. Am J Gastroenterol 103: 162-169, 2008.

24. Hanai H, Takeuchi K, Iida T, Kashiwagi N, Saniabadi AR, Matsushita I, Sato Y, Kasuga N and Nakamura T: Relationship between fecal calprotectin, intestinal inflammation, and peripheral blood neutrophils in patients with active ulcerative colitis. Dig Dis Sci 49: 1438-1443, 2004

25. Kawashima K, Ishihara S, Yuki T, Fukuba N, Oshima N, Kazumori H, Sonoyama H, Yamashita N, Tada Y, Kusunoki R, et al: Fecal calprotectin level correlated with both endoscopic severity and disease extent in ulcerative colitis. BMC Gastroenterol 16: 47, 2016.

26. Ricanek P, Brackmann S, Perminow G, Lyckander LG, Sponheim J, Holme O, Høie O, Rydning A and Vatn MH; IBSEN II Study Group: Evaluation of disease activity in IBD at the time of diagnosis by the use of clinical, biochemical, and fecal markers. Scand J Gastroenterol 46: 1081-1091, 2011. 
27. Jones J, Loftus EV Jr, Panaccione R, Chen LS, Peterson S, McConnell J, Baudhuin L, Hanson K, Feagan BG, Harmsen SW, et al: Relationships between disease activity and serum and fecal biomarkers in patients with Crohn's disease. Clin Gastroenterol Hepatol 6: 1218-1224, 2008.

28. Lin JF, Chen JM, Zuo JH, Yu A, Xiao ZJ, Deng FH, Nie B and Jiang B: Meta-analysis: Fecal calprotectin for assessment of inflammatory bowel disease activity. Inflamm Bowel Dis 20 : $1407-1415,2014$

29. Sipponen T, Kärkkäinen P, Savilahti E, Kolho KL, Nuutinen H, Turunen U and Färkkilä M: Correlation of faecal calprotectin and lactoferrin with an endoscopic score for Crohn's disease and histological findings. Aliment Pharmacol Ther 28: 1221-1229, 2008.

30. Kato J, Hiraoka S, Nakarai A, Takashima S, Inokuchi T and Ichinose M: Fecal immunochemical test as a biomarker for inflammatory bowel diseases: Can it rival fecal calprotectin? Intest Res 14: 5-14, 2016.

31. Ahmad R, Sorrell MF, Batra SK, Dhawan P and Singh AB: Gut permeability and mucosal inflammation: bad, good or context dependent. Mucosal Immunol 10: 307-317, 2017.

32. Haga HJ, Brun JG, Berntzen HB, Cervera R, Khamashta M and Hughes GR: Calprotectin in patients with systemic lupus erythematosus: Relation to clinical and laboratory parameters of disease activity. Lupus 2: 47-50, 1993.

33. Soyfoo MS, Roth J, Vogl T, Pochet R and Decaux G: Phagocyte-specific S100A8/A9 protein levels during disease exacerbations and infections in systemic lupus erythematosus J Rheumatol 36: 2190-2194, 2009.

34. Pepper RJ, Hamour S, Chavele KM, Todd SK, Rasmussen N, Flint S, Lyons PA, Smith KG, Pusey CD, Cook HT, et al: Leukocyte and serum S100A8/S100A9 expression reflects disease activity in ANCA-associated vasculitis and glomerulonephritis. Kidney Int 83: 1150-1158, 2013.

35. De Rycke L, Baeten D, Foell D, Kruithof E, Veys EM, Roth J and De KeyserF: Differential expression and response to anti-TNFalpha treatment of infiltrating versus resident tissue macrophage subsets in autoimmune arthritis. J Pathol 206: 17-27, 2005.

36. Frosch M, Ahlmann M, Vogl T, Wittkowski H, Wulffraat N, Foell D and Roth J: The myeloid-related proteins 8 and 14 complex, a novel ligand of toll-like receptor 4 , and interleukin-1beta form a positive feedback mechanism in systemic-onset juvenile idiopathic arthritis. Arthritis Rheum 60: 883-891, 2009.

37. Hirono K, Foell D, Xing Y, Miyagawa-Tomita S, Ye F, Ahlmann M, Vogl T, Futatani T, Rui C, Yu X, et al: Expression of myeloid-related protein- 8 and -14 in patients with acute Kawasaki disease. J Am Coll Cardiol 48: 1257-1264, 2006.
38. Burkhardt K, Radespiel-Tröger M, Rupprecht HD, GoppeltStruebe M, Riess R, Renders L, Hauser IA and Kunzendorf U: An increase in myeloid-related protein serum levels precedes acute renal allograft rejection. J Am Soc Nephrol 12: 1947-1957, 2001.

39. Leach ST, Yang Z, Messina I, Song C, Geczy CL, Cunningham AM and Day AS: Serum and mucosal S100 proteins, calprotectin (S100A8/S100A9) and S100A12, are elevated at diagnosis in children with inflammatory bowel disease. Scand J Gastroenterol 42: 1321-1331, 2007.

40. Meuwis MA, Vernier-Massouille G, Grimaud JC, Bouhnik Y, Laharie D, Piver E, Seidel L, Colombel JF and Louis E; GETAID (Groupe d'Étude Thérapeutique Des Affections Inflammatoires Digestives): Serum calprotectin as a biomarker for Crohn's disease. J Crohn's Colitis 7: e678-e683, 2013.

41. van Lent PL, Grevers LC, Schelbergen R, Blom A, Geurts J, Sloetjes A, Vogl T, Roth J and van den Berg WB: S100A8 causes a shift toward expression of activatory $\mathrm{Fc} \gamma$ receptors on macrophages via toll-like receptor 4 and regulates Fc $\gamma$ receptor expression in synovium during chronic experimental arthritis. Arthritis Rheum 62: 3353-3364, 2010.

42. Sunahori K, Yamamura M, Yamana J, Takasugi K, Kawashima M, Yamamoto H, Chazin WJ, Nakatani Y, Yui S and Makino H: The S100A8/A9 heterodimer amplifies proinflammatory cytokine production by macrophages via activation of nuclear factor kappa B and p38 mitogen-activated protein kinase in rheumatoid arthritis. Arthritis Res Ther 8: R69, 2006.

43. Loser K, Vogl T, Voskort M, Lueken A, Kupas V, Nacken W, Klenner L, Kuhn A, Foell D, Sorokin L, et al: The Toll-like receptor 4 ligands Mrp8 and Mrp14 are crucial in the development of autoreactive $\mathrm{CD} 8^{+} \mathrm{T}$ cells. Nat Med 16: 713-717, 2010 .

44. Pepper RJ, Wang HH, Rajakaruna GK, Papakrivopoulou E, Vogl T, Pusey CD, Cook HT and Salama AD: S100A8/A9 (calprotectin) is critical for development of glomerulonephritis and promotes inflammatory leukocyte-renal cell interactions. Am J Pathol 185: 1264-1274, 2015.

(i) $\Theta$ This work is licensed under a Creative Commons Attribution-NonCommercial-NoDerivatives 4.0 International (CC BY-NC-ND 4.0) License. 